\title{
Coating Thickness Controlled by Different Protective Atmospheres for A Hot Dipped 0.7mm Thin Steel Slab
}

\author{
Fang FANG ${ }^{1, a,{ }^{*}}$, Li-Xin WANG ${ }^{1, b}$, Xiao-Feng DU ${ }^{1, c}$, Feng HUANG ${ }^{2, d}$ \\ ${ }^{1}$ Research and Development Center, Wuhan Iron and Steel Co., Wuhan, 430080, China \\ ${ }^{2}$ Hubei Key Laboratory of Advanced Technology of Automobile Parts, School of Automotive \\ Engineering, Wuhan University of Technology, Wuhan, 430070, China \\ ahoneyfreda@163.com, bwanglixin@wisco.com, 'duxiaofeng@wisco.com, \\ dhuangfeng@whut.edu.cn
}

${ }^{*}$ Corresponding author

Keywords: Protective Atmosphere, Coating, Hot Dipping.

\begin{abstract}
The zinc based coating weight and thickness under different protective atmospheres and zinc bath chemistries were studied in laboratory by HDPS (hot dipping process simulator). The results show that, the coating had a good adhesion on matrix with no leakage and micro crack, the binder course of coating and matrix was smooth and continue. The coating weight and thickness decreased with increasing hydrogen content in furnace, but changed little for zinc bath chemistry of $0.29 \% \mathrm{Al}-\mathrm{Zn}$ when hydrogen content increased from 10 to $20 \%$, they were almost the same except hydrogen was $5 \%$. The coating weight increased significantly with increasing aluminium content solved in zinc bath, when protective atmosphere was conducted on $20 \% \mathrm{H}_{2}$ appeared the largest gap of coating weight between the two zinc chemistries.
\end{abstract}

\section{Introduction}

In order to lower the auto body weight for reducing fuel consumption and to reduce greenhouse gas emission without deteriorating crashworthiness, the auto industries prefer to use thinner gauge high strength steels for auto body parts. To guarantee their use as auto body parts, corrosion resistance has to be assured by zinc coating ${ }^{[1]}$. As the sheet is drawn out of the bath, delicately controlled high pressure air knives blow specific amounts of the liquid zinc from steel substrate ${ }^{[2]}$. If the coating is too thin, it will not provide the necessary corrosion protection; if it is too thick, the galvanize producer is losing money by over-coating with more zinc than required.

During the continuous annealing a slightly reducing atmosphere, a typically mixture of $\mathrm{H} 2$ and $\mathrm{N} 2$, is employed within the annealing furnace to avoid oxidation of the material, as well as reduce oxides possibly present on the surface steel ${ }^{[3]}$. Moreover, Al is widely added to the galvanizing baths to inhibit the formation of brittle $\mathrm{Fe}-\mathrm{Zn}$ compounds at the steel/molten zinc interface. It is interesting to study the effect of zinc bath chemistry and dew point on galvanizing products performances. The coating weight and thickness were analyzed in this paper with two Al contends added in zinc bath and four protective atmospheres by using hot dipping process simulator.

\section{Experimental Procedure}

The substrate studied in the paper was $0.7 \mathrm{~mm}$ thick with a regular cold-rolled mill finish. HDPS coupons comprised $110 \mathrm{~mm} \times 220 \mathrm{~mm}$ with the long axis of the sample parallel to both the rolling and dipping directions. Samples were cleaned and dried per standard practice ${ }^{[4]}$.

All process protective atmospheres comprised $5-20 \mathrm{H}_{2} / 95-80 \mathrm{~N}_{2}(\mathrm{vol} \%)$ with a constant dew point of $-30^{\circ} \mathrm{C}$. All galvanizing baths were held at $455^{\circ} \mathrm{C}$, were none $\mathrm{Fe}$ solved and contained 
0.15/0.24wt $\%$ dissolved Al. The immersion time for all samples was $4 \mathrm{~s}$. Double samples were produced for all thermal cycles.

Coating quality was taken in the uniform $90 \mathrm{~mm} \times 90 \mathrm{~mm}$ coating area of the coated panel for SEM (HITACHI-S-4300) examination. Surface state (zinc coating weight and thickness) and elemental depth profile after hot dipping by the simulator were analyzed by Glow Discharge Optical Emissivity Spectroscopy (GDOES) using a Horiba Jobin-Yvon Profiler.

Tab.1 The Hot Dipping Process Parameters for Experimental Steel

\begin{tabular}{cccccc}
\hline Code & $\begin{array}{c}\text { Soaking } \\
\text { temp, }{ }^{\circ} \mathrm{C}\end{array}$ & $\begin{array}{c}\text { Dew point, } \\
{ }^{\circ} \mathrm{C}\end{array}$ & $\begin{array}{c}\text { Zinc bath } \\
\text { temperature, }{ }^{\circ} \mathrm{C}\end{array}$ & $\begin{array}{c}\text { Atmosphere, } \\
\mathrm{H}_{2} \%\end{array}$ & $\begin{array}{c}\text { Zinc bath } \\
\text { chemistry }\end{array}$ \\
\hline 1 & 800 & -30 & 455 & 5 & $0.15 \% \mathrm{Al}-\mathrm{Zn}$ \\
2 & 800 & -30 & 455 & 10 & $0.15 \% \mathrm{Al}-\mathrm{Zn}$ \\
3 & 800 & -30 & 455 & 15 & $0.15 \% \mathrm{Al}-\mathrm{Zn}$ \\
4 & 800 & -30 & 455 & 20 & $0.15 \% \mathrm{Al}-\mathrm{Zn}$ \\
5 & 800 & -30 & 455 & 5 & $0.29 \% \mathrm{Al}-\mathrm{Zn}$ \\
6 & 800 & -30 & 455 & 10 & $0.29 \% \mathrm{Al}-\mathrm{Zn}$ \\
7 & 800 & -30 & 455 & 15 & $0.29 \% \mathrm{Al}-\mathrm{Zn}$ \\
8 & 800 & -30 & 455 & 20 & $0.29 \% \mathrm{Al}-\mathrm{Zn}$ \\
\hline
\end{tabular}

\section{Results and Discussions}

The cross sectional morphology of coating was displayed in Fig1. When samples were conducted by the four protective atmosphere and two zinc bath chemistries, the coating had a good adhesion on matrix with no leakage and micro crack, the binder course of coating and matrix was smooth and continue. However, the thickness was obvious with the two zinc bath chemistries. When aluminium soled in bath by $0.15 \%$, the coating was thinner that no more than $8 \mu \mathrm{m}$. When aluminium increased to $0.29 \%$, the coating became thicker. The detailed data were shown in Fig2.

The coating weight increased significantly with increasing aluminium content solved in zinc bath. The red mesh displayed bath chemistry of $0.29 \% \mathrm{Al}-\mathrm{Zn}$, and the black solid displayed $0.15 \% \mathrm{al}-\mathrm{Zn}$, the largest gap of coating weight between the two zinc chemistries appeared when protective atmosphere was conducted on $20 \% \mathrm{H}_{2}$, almost $50 \mathrm{~g} / \mathrm{m}^{2}$ heavier for $0.29 \% \mathrm{Al}-\mathrm{Zn}$. The aluminium content had great affection on coating quality.

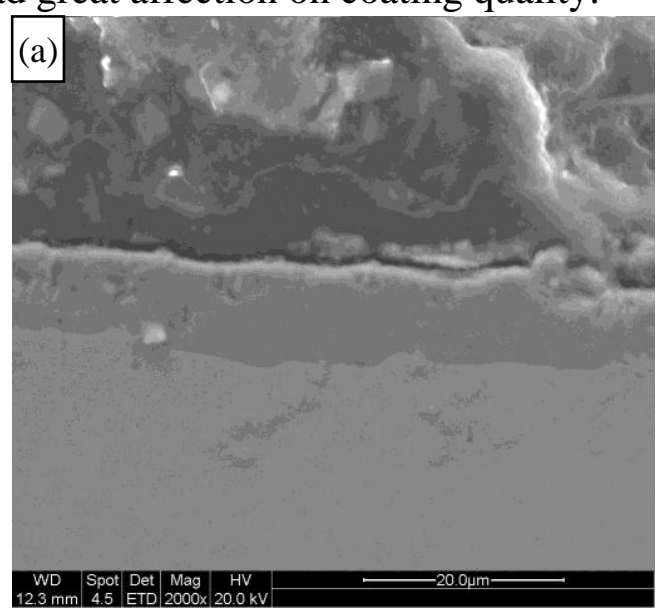

(a) $0.15 \% \mathrm{Al}-\mathrm{Zn}$

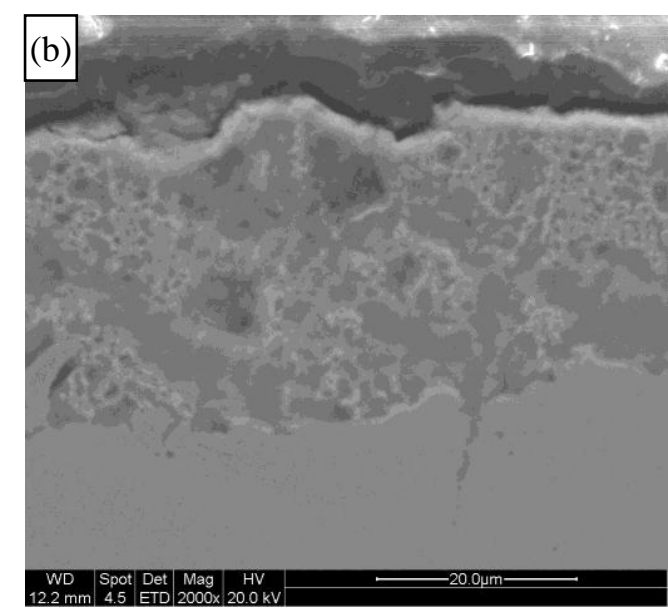

(b) $0.29 \% \mathrm{Al}-\mathrm{Zn}$

Fig.1 Cross-section Morphology of the Experimental Steel for Two Zinc Bath Chemistry 

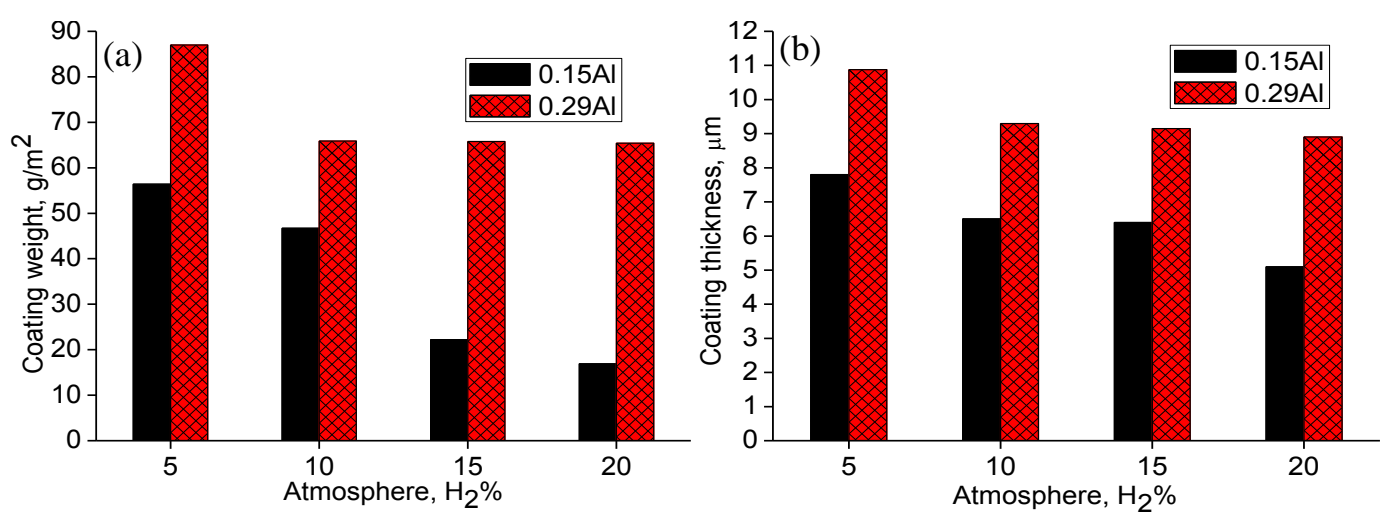

Fig.2 Effect of Zinc Bath Chemistry on (a) Coating Weight and (b) Thickness

The effect of protective atmosphere on coating quality was shown in Fig 3 . The alternation trend displayed that with increasing hydrogen content in furnace, the coating weight and thickness decreased. The trend was more obvious for zinc bath chemistry of $0.15 \% \mathrm{Al}-\mathrm{Zn}$, the weight was decreased from 56.4 to $16.9 \mathrm{~g} / \mathrm{m}^{2}$, and thickness from 7.8 to $5.1 \mu \mathrm{m}$. However, the coating weight and thickness changed little for zinc bath chemistry of $0.29 \% \mathrm{Al}-\mathrm{Zn}$ when hydrogen content increased from 10 to $20 \%$, they were almost the same except hydrogen was $5 \%$. The data of weight were $87,65.89,65.76,65.4 \mathrm{~g} / \mathrm{m}^{2}$, and the thickness were $10.88,9.3,9.15,8.9 \mu \mathrm{m}$ for hydrogen content from $5 \%$ to $20 \%$.

As shown in Fig 1, the coating surface was smooth with no leakage, which rendered that the coats had good adhesion with matrix under the four protective atmospheres and two zinc bath chemistries. When samples were dipped in the zinc bath, aluminium in the bath will first react with iron to form $\mathrm{Fe}_{2} \mathrm{Al}_{5}$ as inhibition layer. With continuous inhibition layer between zinc and matrix, their reaction will be inhibited in a very short time. The protective atmosphere was hydrogen with nitrogen that has the ability to reduce oxides on sample surface. The higher content of aluminium $(0.29 \% \mathrm{Al})$ has the ability to react with $\mathrm{Fe}$ further after the formation of inhibition layer to form thicker coating, but when the reduction effect has completed, the hydrogen content will have no significant effect on coating, so that the coating weight and thickness will be controlled mainly by air knife parameters at this moment.
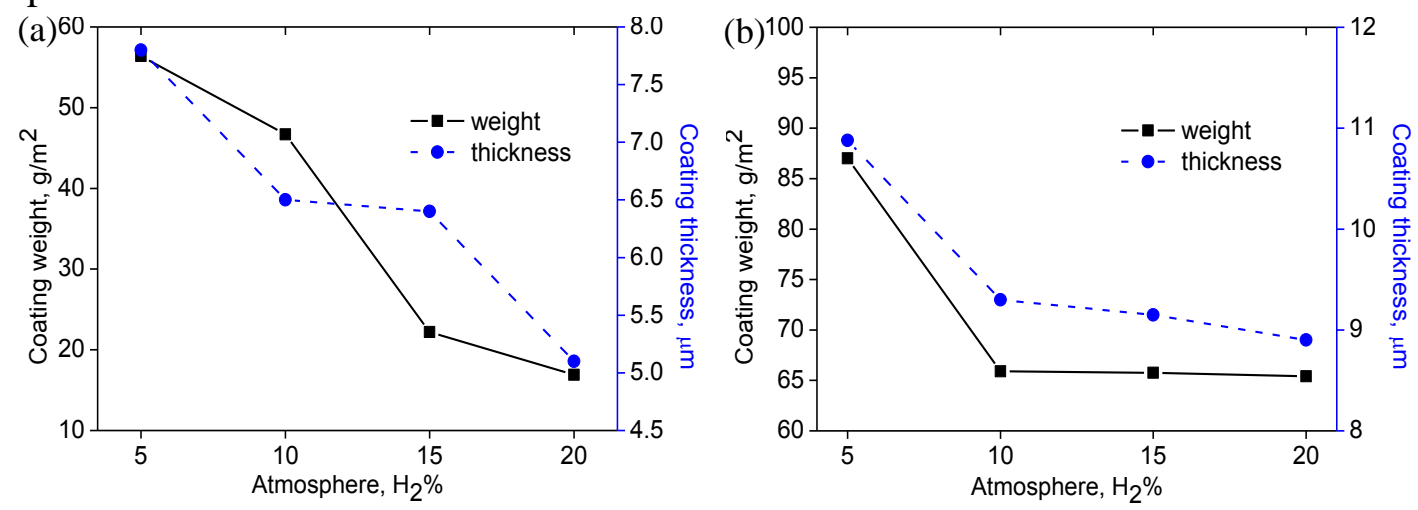

Fig.3 Effect of Atmosphere on Coating Weight and Thickness 0.15\%Al-Zn; (b) $0.29 \% \mathrm{Al}-\mathrm{Zn}$

\section{Conclusions}

The coating weight increased significantly with increasing aluminium content solved in zinc bath, the largest gap of coating weight between the two zinc chemistries appeared when protective atmosphere was conducted on $20 \% \mathrm{H}_{2}$, almost $50 \mathrm{~g} / \mathrm{m}^{2}$ heavier for $0.29 \% \mathrm{Al}-\mathrm{Zn}$. The coating had a good adhesion on matrix with no leakage and micro crack, the binder course of coating and matrix was smooth and continue. The alternation trend of protective atmosphere on coating quality displayed the coating weight and thickness decreased with increasing hydrogen content in furnace. 
But the coating weight and thickness changed little for zinc bath chemistry of $0.29 \% \mathrm{Al}-\mathrm{Zn}$ when hydrogen content increased from 10 to $20 \%$; they were almost the same except hydrogen was $5 \%$.

\section{References}

[1] A. Chakraborty, M. Dutta a, R. Pais b, R.K. Ray. Analysis of an uncommon coating defect on industrial galvannealed high strength interstitial free steel. Surface \& Coatings Technology, 204 (2010) 3481-3489.

[2] Christopher Burnett, Bernd Harand and Roger Zhang. Measurement of Zinc/Magnesium Coatings Utilizing Online XRF Sensors, GALVATECH 2013, 323.

[3] J. P. Guimarães1, A. H. A. Barbosa2, B. M. Gonzalez3, R. R. Vieira. Effect of the Atmosphere Dew Point of Continuous Annealing Furnaces on the Quality of GA Coating on Dual Phase Steel. Galvatech 2015 Proceedings (C) 2015 by AIST, 88-95.

[4] Bellhouse, E.M., McDermid, J.R. Selective Oxidation and Reactive Wetting during Hot-Dip Galvanizing of a $1.0 \% \mathrm{Al}-0.5 \%$ Si TRIP-Assisted Steel [J]. Metall. Mater. Trans. A, 2012, 43A:2426-2441. 